\title{
Contribuições do arranjo "Equipe de Referência" a um Centro de Atenção Psicossocial
}

\section{Contributions arrangement "Reference Team" to a Psychosocial Care Center}

\section{Brunna Lisita Chaves*}

Pontifícia Universidade Católica de Goiás-PUC-Goiás, Goiânia, Goiás, Brasil

\author{
Renata F. Pegoraro**
}

Pontifícia Universidade Católica de Goiás-PUC-Goiás, Goiânia, Goiás, Brasil

\begin{abstract}
RESUMO
O presente estudo é uma pesquisa qualitativa, de caráter exploratório e descritivo, cujo objetivo foi investigar as contribuições do arranjo de "Equipe de Referência" a um Centro de Atenção Psicossocial (CAPS) a partir da perspectiva dos profissionais. Uma equipe de referência é composta por dois ou mais profissionais e é responsável pela confecção e acompanhamento dos projetos terapêuticos de cada usuário do CAPS. Foram entrevistados quatro profissionais componentes da mesma Miniequipe de Referência utilizando roteiro semi estruturado. A análise do conteúdo indicou satisfação no trabalho com esse arranjo, tendo em vista a possibilidade de dividir responsabilidades e somar conhecimentos sobre os usuários. Revelou ainda o distanciamento entre a prática exercida e as produções acadêmicas sobre o arranjo de equipe de referência tendo em vista o desconhecimento, por parte dos profissionais, da existência desse modelo em outros serviços de saúde mental.
\end{abstract}

Palavras-chave: Reforma Psiquiátrica, Centro de Atenção Psicossocial, Equipe

\section{ABSTRACT}

This study is a qualitative, exploratory and descriptive, whose objective was to investigate the contributions of the arrangement of "Reference Team" to a Center for Psychosocial Care (CAPS) from the perspective of professionals. A reference team is composed of two or more professionals and is responsible for the preparation and monitoring of therapeutic projects for each user of CAPS. We interviewed four professional components of the same MiniReference staff using semi-structured. The content analysis indicated job satisfaction with this arrangement, in view of the possibility of sharing responsibilities and add knowledge about users. Also revealed the gap between practice and academic productions performed on the array reference team in order to ignorance on the part of professionals, the existence of this model in other mental health services.

Keywords: Psychiatric Peform, Center for Psychosocial Care, Team 


\section{I ntrodução}

O fim dos 1970, no Brasil, foi caracterizado pela constante mobilização da sociedade civil rumo à transformação do modelo sociopolítico e pela redemocratização do Estado após 20 anos de ditadura militar (AMARANTE, 1995). No âmbito da saúde brasileira, durante este mesmo período, começaram a "emergir críticas à ineficiência da assistência pública em saúde e ao caráter privatista da política de saúde do governo central" (TENÓRIO, 2002, p. 32).

A crítica às políticas de saúde do Estado cooperou para construção do Movimento da Reforma Sanitária, segundo o qual haveria necessidade de administração e planejamento dos serviços de saúde, bem como, ampliação do acesso da população a assistência à saúde, defendendo que o "aperfeiçoamento técnico e o gerenciamento honesto e competente dos recursos da ciência médica pela gestão pública resolveriam o problema da má assistência em saúde, inclusive no setor psiquiátrico" (TENÓRIO, 2002, p. 32).

Ao mesmo tempo em que o movimento de reforma sanitária crescia, o modelo assistencial no campo psiquiátrico vinha recebendo críticas devido à trágica situação dos hospitais especializados. Dentre o rol de críticas, encontravam-se denúncias sobre fraudes no sistema de financiamento dos serviços e situações de abandono, violência e maus-tratos aos pacientes internados nos manicômios brasileiros. A partir da década de 70, tais denúncias estimularam a luta em prol da desinstitucionalização no campo da saúde mental e da humanização dos tratamentos psiquiátricos (AMARANTE, 1995; TENÓRIO, 2002).

Diferentes instituições, entidades, militâncias e movimentos se envolveram na formulação das políticas de saúde mental no Brasil neste momento e, em 1978, foi criado o MTSM - Movimento dos Trabalhadores em Saúde Mental (AMARANTE, 2007). Composto por profissionais de todas as categorias, simpatizantes não técnicos da saúde, usuários dos serviços (termo empregado no lugar de 'pacientes') juntamente com seus familiares e constituído em um espaço de luta não institucional, o MTSM foi considerado o ator político fundamental da Reforma Psiquiátrica, que é considerada como um

[...] processo histórico de formulação crítica e prática, que teve como objetivos e estratégias o questionamento e elaboração de propostas de transformação do modelo clássico e do paradigma da psiquiatria (AMARANTE, 1995, p. 87).

A tarefa da Reforma Psiquiátrica Brasileira não era aperfeiçoar as estruturas tradicionais de assistência em saúde mental, ou seja, o ambulatório e o manicômio, mas inventar novos dispositivos e novas tecnologias de cuidado. Sua tarefa consistia, portanto, em substituir uma psiquiatria centrada no hospital por uma psiquiatria sustentada 
em dispositivos diversificados, abertos e de natureza comunitária ou "territorial" (TENÓRIO, 2002). O processo de revisão da legislação que regulamentava a atenção psiquiátrica no Brasil teve início em 1989 com o projeto de lei no 3.657/89, nomeado posteriormente, como Lei da Reforma Psiquiátrica. Simples e com apenas 3 artigos de conteúdo, este projeto enfrentou dificuldades no Senado, e em seu lugar, foi aprovado, após dez anos, um projeto substituto, composto por artigos ambíguos quanto à regulamentação da internação e tímido quanto à substituição asilar. Somente em 6 de abril de 2001, com a volta do texto à Câmara dos Deputados, é que aprovou-se a Lei 10.216, considerada uma lei progressista que regulamentou a Reforma Psiquiátrica no Brasil pelos atores envolvidos neste processo (TENÓRIO, 2002).

Desde então, intensificou-se por todo país, a redução gradual e planejada de leitos em hospitais psiquiátricos e a implantação dos serviços substitutivos ao modelo hospitalar manicomial, tendo como eixo os Centros de Atenção Psicossocial (PEREIRA, 2007; BRASIL, 2004).

Os Centros de Atenção Psicossocial (CAPS) atualmente são regulamentados pela Portaria no 336/GM, de 19 de fevereiro de 2002 - e integram a rede do SUS como serviços abertos e comunitários que prestam atendimento e cuidado clínico diário às pessoas com transtornos mentais graves e persistentes, tendo por objetivo a reabilitação psicossocial de seus usuários através de ações intersetoriais (BRASIL, 2005). A reabilitação psicossocial, proposta pela portaria que regulamenta os CAPS, pode ser caracterizada pelo conjunto de ações que se destinam a aumentar as habilidades do indivíduo, diminuindo os danos causados pelo transtorno mental e reinserindo-o no contexto social, afim de resgatar a autonomia de suas funções na comunidade (PITTA apud LUSSI; PEREIRA; JÚNIOR, 2006).

Para realizar tal intento, é de responsabilidade dos CAPS, organizar a rede de serviços de saúde mental de seu território e posicionar-se como referência para os demais serviços envolvidos com o sofrimento mental (BRASIL, 2005).

Com relação ao funcionamento dos CAPS, as portarias nำ336/02 e 189/02 estabeleceram modalidades (AMARANTE, 2007) de acordo com o porte, a capacidade de atendimento e a clientela atendida, organizando-os no país de acordo com o perfil populacional dos municípios brasileiros. Os CAPS são classificados em: CAPS I para municípios entre 20.000 e 50.000 habitantes; CAPS II para regiões entre 70.000 e 200.000 habitantes; CAPS III para municípios com população acima de 200.000 habitantes, com funcionamento durante 24 horas, todos os dias da semana e em feriados. Os CAPS I e II funcionam apenas de segunda à sexta-feira. Além dessas modalidades, há ainda o CAPSi, para atendimento de crianças e 
adolescentes com transtornos mentais, e o CAPSad, para usuários com transtornos decorrentes do abuso de álcool e outras drogas (BRASIL, 2004; 2005).

Os CAPS, em sua rotina diária, oferecem diferentes recursos terapêuticos, como psicoterapia individual ou em grupo, oficinas terapêuticas, atividades comunitárias, atividades artísticas, orientação e acompanhamento do uso de medicação, atendimento domiciliar e aos familiares. As atividades são feitas com usuários e/ou familiares, e podem ser realizadas na comunidade, no trabalho e em diferentes contextos sociais, como parte de uma estratégia terapêutica de reabilitação psicossocial, que poderá ser iniciada ou articulada pelo CAPS (BRASI L, 2004).

Ao final de 2010, a rede de CAPS existente no território brasileiro chegou a 1620 serviços implantados, com cobertura de 0.66 CAPS por 100.000 habitantes. O estado de Goiás em específico, comporta atualmente 30 unidades, sendo a cidade de Goiânia, responsável pelo funcionamento de sete unidades, sendo quatro CAPS II, um CAPSi (que atende crianças e adolescentes com até 18 anos) e dois CAPSad, um destinado a crianças e adolescentes e o outro para população adulta (BRASIL, 2011).

O considerável aumento destes equipamentos substitutivos vem despertando interesse "pela qualificação dos serviços oferecidos, demandando a elaboração de novas formas de trabalho clínico e organização institucional" (MIRANDA; ONOCKO CAMPOS, 2008, p. 908) afim de, garantir conteúdos compatíveis com os princípios éticos da Reforma Psiquiátrica (FURTADO; MIRANDA, 2006).

Dentre os novos arranjos que tentam garantir a efetiva ruptura com o paradigma anterior, manicomial, encontra-se o modelo de gestão colegiada, apoio matricial, assembleias, supervisão clinícoinstitucional e o dispositivo "técnicos de referência" (FURTADO; MIRANDA, 2006, p. 510).

De acordo com a cartilha sobre CAPS elaborada pelo Ministério da Saúde (2004), cabe ao técnico de referência: a) aproximar-se de maneira especial de certo número de usuários e assisti-los de modo singular, tornando-se responsável pela elaboração e monitoramento do projeto terapêutico individual (PT), isto é, de um conjunto de atividades destinadas ao usuário de acordo com sua particularidade, para serem realizados durante sua permanência no serviço; b) fazer contato com os familiares do usuário; e c) avaliar periodicamente as metas traçadas no projeto (CADORE; PALMA; DASSOLER, 2010; MIRANDA; ONOCKO CAMPOS, 2008; FURTADO; MIRANDA, 2006).

Com o objetivo de deslocar o poder das profissões e corporações de especialistas, Campos (1999) recomendou a adoção de um novo sistema de referência entre profissionais e usuários, não mais centrado na ação de um único profissional, o técnico de referência, mas em uma 'Equipe de Referência'. Este rearranjo estimularia a 
produção de novos padrões de inter-relação entre equipe e usuários, ampliaria o compromisso dos profissionais com a produção de saúde e quebraria os obstáculos de ordem organizacionais que dificultam a comunicação (CAMPOS, 1999; FURTADO, 2007).

Além de ser um arranjo ou modelo destinado a concretizar e potencializar o compartilhamento de práticas e saber, a organização de serviços segundo a proposta de Equipes de Referência seria feita:

- por equipes multiprofissionais com dois, três ou mais profissionais, organizados conforme o objetivo e a clientela (CAMPOS, 1999);

- mediante a construção do projeto terapêutico (PT) que se daria, em geral, a partir de várias perspectivas e com base na interação entre o usuário e seus profissionais de referência, nas interlocuções destes últimos entre si e com outros grupos como família, instituições de saúde, setores culturais, socioeducacionais, entre outros (FURTADO; MIRANDA, 2006);

- de modo a garantir que as atividades do PT fossem executadas por um conjunto amplo de trabalhadores possibilitando a composição interdisciplinar do PT, sem diluir a responsabilidade das equipes na condução dos casos (CAMPOS, 1999);

- pela capacidade da equipe acionar apoio de outros profissionais e de outra equipe conforme 0 entendimento adquirido sobre o caso (CAMPOS, 1999).

Toda esta reorganização pretende facilitar o desenvolvimento da vinculação do usuário com mais de um profissional, permitindo estabelecimento de outros laços afetivos, além de aumentar a circulação de conhecimentos e promover o compartilhamento das incumbências práticas e das vivências afetivas (MIRANDA; ONOCKO CAMPOS, 2008).

Em várias cidades brasileiras, existem iniciativas em atenção básica, na saúde mental e em hospitais gerais públicos que vêm relatando êxitos mediante a reorganização de suas equipes, favorecendo a colaboração interprofissional (FURTADO, 2007). Esta adesão crescente ao novo arranjo foi confirmada pela pesquisa do Ministério da Saúde (2008) que

[...] avaliou $78,88 \%$ dos CAPS existentes a época no país e
constatou que $49 \%$ destes trabalham a partir do técnico de
referência e $31,8 \%$ utilizam o modelo de miniequipes de
profissionais de referência como dispositivos de
acompanhamento dos projetos terapêuticos (BRASIL apud
MIRANDA; ONOCKO CAMPOS, 2010).

Contudo, ainda são escassos os estudos científicos que avaliam a implantação e o impacto do arranjo de equipe de referência em contexto específico da saúde mental, limitando até o embasamento teórico dos profissionais da área (MIRANDA; ONOCKO CAMPOS, 2008; 2010). 
Por considerar as restritas análises e debates sobre a lógica de Equipes de Referência e a importância da avaliação sistemática das várias experiências em curso (FURTADO, 2007), este trabalho teve como objetivo investigar as concepções dos profissionais de um CAPS II da cidade de Goiânia sobre o funcionamento de uma MiniEquipe de Referência, e mais especificamente, identificar os critérios para formação e implantação de MiniEquipe no CAPS, pontos positivos e negativos para executar o trabalho em Miniequipe e os critérios de encaminhamento dos usuários para MiniEquipe.

\section{Método}

\subsection{Participantes}

Participaram do estudo quatro profissionais de um Centro de Atenção Psicossocial II (CAPS) da cidade de Goiânia. Todos os participantes eram mulheres e, deste modo, serão identificadas, no decorrer do trabalho, pela letra $\mathrm{E}$ (entrevistada), seguido dos números $1,2,3 \mathrm{e}$ 4, de acordo com a ordem da coleta dos dados. "E1" para a que cedeu a primeira entrevista, e assim, sucessivamente.

A idade das participantes variou entre 33 e 52 anos. O tempo de experiência em serviços de saúde mental variou de 2 anos e 6 meses a 10 anos e a experiência com trabalho em Miniequipe variou de 2 anos e 6 meses a 5 anos. Todas eram componentes da mesma MiniEquipe de Referência, trabalhavam no turno matutino e vespertino, cumpriam a carga horária de 30 horas/semanais, e possuíam formação superior (Psicologia, Enfermagem, Musicoterapia, Medicina). Quanto à pós-graduação, 3 possuiam formação LatoSensu, e 1 delas era Mestre em Ciências da Saúde.

Os critérios utilizados para a seleção das entrevistadas foram: ser profissional de nível superior; fazer parte do quadro de profissionais da instituição pesquisada por, no mínimo, seis meses; serem integrantes da mesma Miniequipe de Referência e apresentar disponibilidade para fornecer entrevista longa, gravada, mediante sigilo de identificação.

A escolha da Miniequipe de referência deu-se também pelo critério de conveniência, pois suas integrantes trabalhavam no mesmo turno em que uma das pesquisadoras tinha disponibilidade para executar a coleta.

\subsection{Local}

O local desta investigação, um Centro de Atenção Psicossocial - CAPS II, situado na cidade de Goiânia, iniciou seu funcionamento em abril 
de 2003 e destina seus serviços a portadores de Transtorno Mental Grave, maiores de 18 anos, não usuários de álcool ou outras drogas.

A equipe do CAPS era formada, à época, por 45 profissionais: 4 Psicólogas, 3 Médicos Psiquiatras, 2 Professores de Educação Física, 2 Assistentes Sociais, 2 Enfermeiras, 1 Musicoterapeuta, 2 Terapeutas Ocupacionais, 1 Artista Plástica, 2 Arte Terapeutas, 1 Farmacêutica, 6 Assistentes Administrativos que revezavam entre turno matutino e vespertino, 1 Gestora Geral, 1 Gestora Administrativa, 1 Gestora Técnica, 9 Técnicos de Enfermagem e 7 Funcionários da área auxiliar e serviços gerais, além de dois estagiários (Psicologia e Educação Física). A equipe técnica formada pelos profissionais da saúde era divida em 4 Miniequipes de Referência e 1 Grupo de Acolhimento.

No mês de setembro de 2011 foram atendidos 439 usuários, distribuídos nas três modalidades de atendimento previstas na legislação (BRASIL, 2004): intensivo (o usuário passa o dia todo), semi-intensivo (usuário frequenta no mínimo uma vez por semana) e não intensivo (comparece para atendimentos agendados); e eram disponibilizados à época, 32 tipos de atividades como: grupos psicoterápicos, atividades físicas, atividades artesanais, grupos de música, oficinas de desenho e pintura e grupos informativos. Essas atividades tinham por objetivo o desenvolvimento cognitivo, intelectual e motor, além da socialização do usuário e a reinserção na comunidade.

O horário de funcionamento da unidade era de 2a a 6a feira das 7 às 18 horas e o acolhimento de novos usuários era caracterizado pelo modelo "Porta aberta", no qual se acolhiam todos os sujeitos que procurassem 0 serviço sem necessidade de agendamento. Semanalmente, acontecia a Reunião de Equipe, na qual deviam estar presentes todos os profissionais da equipe técnica e que tinha por objetivo discutir todas as questões que surgissem no decorrer da semana referentes à equipe, aos usuários e familiares, além de realizar informes sobre temas relacionados ao serviço.

\subsection{Tipo de estudo}

Trata-se de um estudo do tipo exploratório e descritivo, desenvolvido a partir da perspectiva qualitativa, que visa interpretar e compreender os fenômenos sociais, estudados em seu ambiente natural, a partir de falas ou palavras sobre o sentido que as pessoas atribuem às suas experiências (POPE; MAYS, 2005).

\subsection{I nstrumentos}

Utilizou-se como métodos para coleta dos dados a observação participante, registros da pesquisadora caracterizados pelo diário de campo e entrevista semiestruturada composta por tópicos que 
abordavam: dados gerais de caracterização do entrevistado; avaliação sobre o trabalho em equipe; função e rotina da Miniequipe (ME); critérios de encaminhamento para ME; número de usuários da ME e avaliação do entrevistado sobre: o perfil dos usuários do CAPS, a participação dos familiares no tratamento dos usuários e sobre a rede de saúde mental do município.

Durante as entrevistas, utilizou-se gravador digital, prancheta, caneta, duas cadeiras e o ambiente escolhido foi uma sala do CAPS que estava disponível no horário das entrevistas.

\subsection{Procedimento}

A entrada em campo foi marcada pela discussão entre pesquisadores e gestores técnicos sobre o trabalho em equipe naquele CAPS. Como subprojeto da pesquisa "Saúde Mental na Rede Pública de Goiânia: concepções sobre o cuidado prestado segundo usuários, familiares e profissionais de um Centro de Atenção Psicossocial", este estudo foi autorizado pela Secretaria Municipal de Saúde (agosto 2011) e aprovado pelo Comitê de Ética da Pontifícia Universidade Católica de Goiás (setembro de 2011), através do Parecer CEP/SGC 1840/2011. Após emissão do parecer, houve uma reunião entre a gestora técnica e os pesquisadores para definição do início da coleta de dados, bem como dos critérios de escolha da Miniequipe (anteriormente descritos no item "Participantes"). Um pesquisador convidou individualmente as profissionais da Miniequipe escolhida e mediante o aceite, foram agendados datas e horários para a coleta das informações. As entrevistas foram realizadas na própria instituição, durante o mês de outubro de 2011.

As entrevistadas receberam uma carta explicativa sobre a pesquisa, com o intuito de detalhar o estudo e obter consentimento para a realização da entrevista. Após explicação sobre a carta, foi entregue a cada participante o "Termo de Consentimento Livre e Esclarecido"(TCLE), em duas vias, que garantia o anonimato, a confidencialidade dos dados coletados e assegurava sua livre participação na pesquisa.

As entrevistas foram gravadas em áudio, transcritas na íntegra e posteriormente procedeu-se à análise temática das mesmas. Para tal, foram seguidos alguns passos, conforme orientam Biasoli-Alves e Dias da Silva (1992): a) leitura exaustiva e repetida de cada entrevista; b) leitura do conjunto de entrevistas; c) identificação de temas e subtemas no conjunto de entrevistas; d) redação das categorias encontradas e confronto dessas categorias com a literatura da área para discussão posterior das mesmas.

\section{Resultados}


Da análise das entrevistas com as profissionais, apreendeu-se duas grandes categorias, sendo cada uma delas, composta por subcategorias. São elas: a) CAPS: perfil dos usuários, pontos positivos e barreiras e b) Formação e funcionamento das Miniequipes. A seguir as categorias serão descritas:

\section{a) CAPS: perfil dos usuários, pontos positivos e barreiras}

De acordo com as entrevistadas, o perfil do usuário tem mudado no decorrer do tempo, sendo que alguns anos atrás, a maioria era "comprometida", e hoje, frequentam o serviço grande número de usuários estáveis com diagnósticos de transtornos "mais leves", como transtornos de humor, ansiedade e personalidade.

As entrevistadas relataram acreditar neste modelo de atenção biopsicossocial e destacaram pontos positivos e negativos da rotina do CAPS. Dentre os pontos considerados como positivos foram apontados: a troca de conhecimento entre os profissionais (trabalho interdisciplinar), ausência de hierarquia entre gestores e profissionais, valorização do ponto de vista do usuário e do familiar pelos profissionais da saúde, empenho dos profissionais e alto nível de profissionalização. Já entre as dificuldades encontram-se questões referentes à: a) estrutura: espaço físico inadequado, falta de medicação na rede, não ter supervisão clínico-institucional e falta de capacitação permanente de recursos humanos; b) dinâmica do serviço: pouco conhecimento sobre todos os usuários do serviço e não ter perfil de usuário delimitado; c) 'relações': adoecimento nas relações de equipe, a mistura de valores pessoais no trabalho e ausência de vínculo dos profissionais com os familiares dos usuários. Algumas falas ilustram essas dificuldades:

Outro problema eu vejo que é a capacitação permanente de recursos humanos [...] Eu acho que é um ambiente extremamente desorganizado, e ele precisa ser organizado, ele precisa ter normas, precisa ter rotinas e serem cumpridas. (E1)

Então a equipe necessita de estar tendo uma supervisão constante de alguém de fora. Isso já foi solicitado em alguns momentos cruciais de alguns funcionários, mas ainda não se levo isso a serio... (E2)

Chega um usuário que nem é desse serviço, assim, a equipe tinha dúvida se ele era desse serviço ou não [...] Se você tivesse aprofundado desde o começo, talvez você veria que não era o caso de você cronificar a pessoa tomando remédio e tal. (E4) 
Tem-se como queixa principal, a falta de suporte na rede para atendimento aos usuários em serviços fora do CAPS. Os agendamentos das consultas médicas solicitadas pelo psiquiatra são demorados, sendo necessário às vezes, realizar atendimento clínico no próprio CAPS, fator ilustrado pelo relato a seguir:

[...] então como a gente só consegue chegar no especialista através de encaminhamento, muitas vezes a gente faz o atendimento psiquiátrico e clínico aqui mesmo, né?... porque ele [usuário] tem dificuldade de ir por falta de vaga ou quando sai [a vaga], sai longe [...] (E2)

\section{b) Formação e funcionamento das Miniequipes}

\section{b.1) Atividades realizadas pela Miniequipe}

As profissionais relataram de forma unânime as seguintes atividades como de responsabilidade da Miniequipe: reunião semanal para discussão dos casos que serão atendidos pela médica durante a semana; visita domiciliar; grupo de medicação (atendimento pelo médico psiquiatra acompanhado por um profissional da ME); fazer APAC (Autorização de Procedimentos Ambulatoriais de Alta Complexidade/Custo) e discussão de casos com demanda de intervenção imediata, como tentativa de suicídio e atenção à crise. Ressaltaram ainda que a Miniequipe é um arranjo que está inserido em uma equipe maior, por isso, têm como atividade também a reunião semanal de equipe.

\section{b.2) Função da Miniequipe}

Ao analisar as concepções das entrevistadas, observou-se que há confusão entre a função e as tarefas desempenhadas pela ME. Foram destacadas como funções: definir em conjunto, o Projeto Terapêutico dos usuários; discussão semanal de casos; oferecer atendimento aos familiares; atender intercorrências; estabelecer ligação entre usuário e a unidade e discutir o funcionamento da unidade.

A função da ME é responder pelos usuários que fazem parte dessa ME. Esse acompanhamento integral, né? De saber o que esta acontecendo, a questão da saúde, as questões familiares [...] (E3)

"Acho que ser uma referencia pro usuário dela, né?. Ser uma referencia em todos os sentidos" [...] (E4)

\section{b.3) Critérios de formação das Miniequipes}


Apesar de não formalizados pelo serviço, os critérios de formação das ME parecem ser conhecidos pelas trabalhadoras. Elas relataram como condições importantes: a indicação do gestor; a disponibilidade de horário do profissional para participar das reuniões semanais da ME e profissionais com formações diferenciadas por $M E$, de forma a se garantir a multidisciplinaridade.

Entretanto, o critério que se repetiu em todos os relatos, foi a quantidade de trabalhadores, sendo o objetivo principal, distribuí-los igualmente pelas Miniequipes.

“Então eu acho que ela se compõe aqui no CAPS observando a quantidade de profissionais por cada ME". (E1)

\section{b.4) Critérios de encaminhamento dos usuários para as Miniequipes}

São de conhecimento das profissionais dois critérios de encaminhamento: 1) a quantidade de usuários por $M E$, na qual objetiva-se manter em média a mesma quantidade entre as ME; 2 ) o vínculo do usuário com algum membro da miniequipe, critério melhor compreendido no discurso do E4:

“Então, de repente, a pessoa vai fazer um grupo comigo, eles colocam na minha ME pra que eu tenha um contato e um vínculo. Esse é um critério". (E4)

\section{b.5) Conhecimento teórico sobre o arranjo de Miniequipe}

Todas as trabalhadoras relataram que este arranjo de ME foi implantado na gestão anterior, acerca de 6 anos (diário de campo), e que não possuiam conhecimento sobre o embasamento teórico dessa proposta.

No relato da E4 também é possível perceber a falta de conhecimento sobre a implantação deste arranjo em outros serviços:

“Eu não conheço outro lugar que tenha [...] Essa idéia acho que só tem aqui. Não sei se o Abel [nome fictício do antigo Gestor Técnico] viu isso em algum outro Estado". (E4)

\section{b.6) Relação com familiares}

Uma única questão abordou a relação da Miniequipe com os familiares. Ficou explicito que no momento da pesquisa as entrevistadas consideravam este aspecto de grande importância para um tratamento bem sucedido, entretanto, não desenvolviam atividades voltadas às famílias dos usuários. 
"Eu acho que a gente precisa resgatar isso, fazer esse vínculo, fortalecer esse vínculo". (E1)

No início do tratamento, há vinculação dos familiares com o serviço através do grupo direcionado aos cuidadores, mas este contato se perde ao longo do tratamento devido a fatores como: a falta de tempo em decorrência do volume de atividades desenvolvidas por cada profissional:

No momento não se realiza um atendimento exclusivo aos familiares... Nessa ME já foram realizadas um tempo atrás as reuniões com familiares, e exatamente devido à demanda e o pouco tempo que nós temos, foram suspensas essas reuniões de familiares. (E3)

\section{b.7) Pontos Negativos e dificuldades do arranjo de Miniequipe}

No que diz respeito às dificuldades enfrentadas pela Miniequipe, as entrevistadas consideraram o grande número de usuários por ME como fator principal. Elas declararam que não há condição de diminuir a quantidade de usuários por ME, pois o CAPS é um serviço público e deve atender a toda demanda social, mas alegam que este fator influencia na qualidade do atendimento oferecido a cada usuário.

Realmente é essa a demanda, né? Mas eu acho que nós não conseguimos acompanhar adequadamente todos os usuários. Em função disso, às vezes fica visita domiciliar sem fazer, as próprias reuniões de família, né?. (E3)

As participantes ressaltaram ainda como dificuldade, a sobrecarga de trabalho, caracterizada por atividades como: realizar telefonemas, atender intercorrências, fazer APAC (Autorização de Procedimentos de Alta Complexidade), coordenar oficinas e evoluir em prontuários. Esse fator impossibilita o acompanhamento aproximado a todos os usuários da $\mathrm{ME}$, gerando sentimentos de frustração e impotência nas profissionais.

O ponto negativo do arranjo de Miniequipe identificado no discurso das entrevistadas foi a dificuldade apresentada por elas em conhecerem os casos que não façam parte de sua ME, ou seja, o arranjo de ME não proporciona o conhecimento de todos os usuários do serviço. Esta situação sugere uma fragmentação do serviço, nos casos clínicos de usuários de outra ME só são conhecidos pelo profissional, se forem discutidos durante a reunião de semanal de equipe, ou se o profissional coordenar alguma atividade que faça parte do PT do usuário. 
Eu sinto falta de ter um conhecimento mais amplo de um número maior de usuários... Então por falta de um tempo maior, ou pelo grande número de usuários que nós temos, nós ficamos impossibilitados de ter esse acompanhamento tão próximo como nós temos com os [usuários] da nossa Miniequipe. (E3)

\section{b.8) Pontos positivos do arranjo de Miniequipe}

As entrevistadas relataram que o arranjo de ME sofreu mudanças em sua configuração desde a implantação, e que estas ocorreram devido necessidades identificadas no cotidiano do trabalho. Foram elas: a visita domiciliar passou a ser programada; a reunião semanal de ME que era realizada durante meio período do dia se estendeu para o período todo; as discussões de casos passaram a ser evoluídas nos prontuários; o médico psiquiatra foi incluído nas reuniões de suas Miniequipes; e a reunião de ME que tinha por objetivo discutir casos aleatórios identificados no decorrer da semana ganhou um caráter sistematizado, caracterizado como o momento de discussão dos casos que serão atendidos na consulta psiquiátrica da semana.

As entrevistadas analisaram estas mudanças como positivas e facilitadoras do trabalho em Miniequipe.

[...] “Então de lá pra cá foram vários formatos diferentes... Não tinha comunicação. Era muito disperso, não tinha esse formato de discutir que a gente faz hoje". (E4)

Nos discursos, foi possível perceber também a satisfação por trabalharem com este arranjo devido fatores como: a troca de conhecimento entre os profissionais e o olhar biopsicossocial sobre o usuário, proporcionando diferentes recursos de tratamento.

Eu avalio como a melhor coisa. Se eu pudesse ter no meu consultório particular uma Miniequipe... nossa! [...] Um atendimento em saúde mental tem que ser por uma equipe multidisciplinar, já que é uma doença multifatorial $[\ldots]$ (E2)

Outros fatores também foram apontados como positivos. São eles: a atenção integral ao usuário referente da ME e a menor sobrecarga de trabalho, devido as responsabilidades e decisões que são divididas entre todos os membros da Miniequipe.

“E quando compartilha na Miniequipe um problema ele é bem mais rico [...] A riqueza da ME é muito em função desse compartilhamento de decisões". (E1)

\section{Discussão}


De acordo com as entrevistas, o trabalho com arranjo de Miniequipe é positivo, pois o mesmo proporciona um trabalho interdisciplinar, caracterizado pela "troca de conhecimento" entre os profissionais; oferece atendimento em tempo integral ao usuário referente; além de ser um modelo que proporciona a divisão de responsabilidade entre os profissionais, resguardando o desempenho e a saúde emocional dos mesmos.

As características apontadas pelas entrevistadas vão ao encontro do estudo desenvolvido por Miranda e Onocko Campos (2008) que avaliou o trabalho de referência em serviços de Campinas (SP) sob o ponto de vista dos usuários, trabalhadores e familiares. Assim como o presente estudo, a pesquisa também constatou que o arranjo de Miniequipe permitia o compartilhamento dos casos, "diminuindo o desconforto de um trabalho solitário" (MIRANDA; ONOCKO CAMPOS, 2008, p. 910).

Ainda sobre os benefícios deste arranjo, a análise evidenciou que a composição da ME por profissionais de diferentes categorias, responsáveis por um conjunto de tarefas e que visam intervir sobre os mesmos usuários é também característica mencionada por Furtado (2007).

Com relação aos critérios de formação das $M E$, percebeu-se que apesar de não serem formalizados no serviço, eles foram facilmente identificados pelas entrevistadas, tais como: número equivalente de profissionais em cada $\mathrm{ME}$, a multidisciplinaridade, a indicação do gestor e a disponibilidade de horário dos profissionais. Essas características guardam semelhanças com a proposta de Campos (1999), na qual sugere que as equipes de referência tenham sua composição pautada nas condições da própria unidade, com dois, três ou mais profissionais, obedecendo sempre a uma composição multiprofissional e a simples divisão igualitária dentro de cada unidade.

Outra semelhança entre as entrevistas e a literatura pode ser encontrada no artigo de Furtado (2007), que sugere que encontros sistematizados com objetivo de discutir casos novos, avaliar usuários pertencentes à ME e definir ações de tratamento, devem ser garantidos às Miniequipes. Nos relatos das entrevistadas foi possível identificar que neste serviço as Miniequipes possuem este espaço de discussão. Cada ME tem reservado um dia da semana para reunião, durante todo o período de trabalho.

Mesmo com facilidade em avaliar o arranjo de ME e descrever os critérios de formação, observou-se que houve dificuldade das entrevistadas em diferenciar a função e as atividades realizadas pela ME. Esse fator também foi observado no estudo da Miranda e Onocko Campos (2008, p.909) no qual mencionaram que os sujeitos da pesquisa 
[...] identificaram que o trabalho de referência produzia efeitos terapêuticos e contribuía para eficácia da organização do trabalho. Entretanto, os sujeitos mostraram que o trabalho clínico das equipes de referência requeria maior esclarecimento com relação às suas funções.

Uma hipótese para reflexão levantada durante a análise do material é que a dificuldade das profissionais entrevistadas em diferenciar as funções da ME das atividades desempenhadas esteja relacionada à falta de conhecimento teórico sobre a proposta desse arranjo. Ao serem questionadas sobre o embasamento teórico do modelo, foi unanime a falta de conhecimento de publicações que discutam essa temática, ou seja, assim como no estudo de Miranda e Onocko Campos (2008) observa-se, com relação a esse tema, uma falta de articulação entre teoria e prática em seu cotidiano.

Outro ponto relevante identificado no estudo refere-se às dificuldades ressaltadas pelas entrevistadas em trabalhar com modelo de $\mathrm{ME}$, em virtude da centralização da atenção aos usuários de sua $M E$, não tendo conhecimento aprofundado e às vezes nem superficial dos casos de outros usuários do serviço, condição já prevista por Campos (1999) quando propôs a implantação deste modelo em serviços de saúde. Ele alegou que

Se por um lado o sistema de referência facilita o vínculo e a
definição mais clara de responsabilidades, por outro ele
desenvolve alguns antagonismos com o trabalho
interdisciplinar... Nenhum profissional saberia sobre tudo e
cada miniequipe nunca completará toda a potencialidade de
um trabalho interdisciplinar (CAMPOS, 1999, p. 397).

Como ponto negativo foi mencionada a falha na rede assistencial do município, caracterizada pela falta de recursos médicos, sociais e medicamentosos. Esse fator prejudica e dificulta o tratamento dos usuários do serviço, além de acarretar desgastes emocionais aos profissionais, pois o arranjo de ME naturalmente estimula um maior vínculo com os usuários e atribui maior responsabilidade e engajamento pelos profissionais (SILVA; COSTA, 2010).

Com relação ao vínculo da ME com familiares dos usuários referenciados, os relatos apontaram falhas. Devido ao grande volume de trabalho, os profissionais alegaram não desenvolverem atividades voltadas aos cuidadores familiares, mesmo compreendendo que este é um fator determinante ao tratamento dos usuários.

Os resultados da pesquisa indicaram que o objetivo principal deste estudo, de investigar as concepções dos profissionais sobre o arranjo, e os objetivos específicos que abarcavam o funcionamento desse arranjo, foram atingidos, e que poderão ser relevantes a futuras 
pesquisas sobre os serviços substitutivos de saúde mental brasileiros. O estudo aponta, ainda, duas atividades que poderiam contribuir para o aprimoramento do CAPS: solicitar supervisão institucional e implementação de um grupo de estudos, ambos espaços para reflexão da prática de assistência em saúde mental.

A análise do material indicou que o arranjo de Miniequipes de Referência reorganiza o serviço de saúde mental contribuindo com a descentralização do saber, assim como propõem a Reforma Psiquiátrica, e contribui com o tratamento do usuário à medida que este é atendido sob a perspectiva biopsicossocial. Contudo, não é um modelo exclusivo do CAPS de Goiânia estudado, e que apesar dos avanços nos arranjos dos serviços substitutivos em diferentes regiões do país, não há um diálogo entre academia (universidade) e assistência (serviços de saúde mental), permitindo-nos a reflexão de que há uma cisão entre quem escreve (academia) e quem faz saúde mental (serviços), limitando, assim, maior embasamento teórico aos serviços que pretendem aperfeiçoar o campo de trabalho e aos profissionais que já estão inseridos nestas novas práticas.

O presente estudo contribui para a reflexão sobre o arranjo de ME fora da região de Campinas, SP, e de autoria de pesquisadores ligados à Unicamp - Universidade Estadual de Campinas, SP (FURTADO, 2007; MIRANDA; ONOCKO CAMPOS, 2008). A discussão sobre o arranjo de ME fora do Estado de São Paulo permite confirmar a relevância de estudos sobre o funcionamento dos CAPS no Brasil, bem como a similaridade entre as dificuldades e avanços do modelo de ME no campo dos serviços substitutivos de saúde mental.

\section{Referências}

AMARANTE, P. Loucos pela vida: a trajetória da reforma psiquiátrica no Brasil. Rio de Janeiro: Fiocruz, 1995.

AMARANTE, P. Saúde Mental e atenção psicossocial. Rio de J aneiro: Fiocruz, 2007.

BIASOLI-ALVES, Z. M. M.; DIAS-DA-SILVA, M. H. C. F. Análise qualitativa de dados de entrevista. Uma proposta. Paideia Cadernos de Educação, Ribeirão Preto, n. 2 p. 61-69, 1992.

BRASIL. Ministério da Saúde. Reforma psiquiátrica e política de saúde mental no Brasil. In:

Conferência regional de reforma dos serviços de saúde mental: 15 anos depois de Caracas. Brasil, 2005.

Disponível

em:

<http://bvsms.saude.gov.br/bvs/publicacoes/Relatorio15_anos_Cara cas.pdf>. Acesso em: 19 fev. 2011.

BRASIL. Ministério da Saúde. Saúde Mental no SUS: As novas fronteiras da Reforma Psiquiátrica. In: Relatório de gestão 2007/ 2010. Disponível em: 
<http://portal.saude.gov.br/portal/arquivos/pdf/gestao2007_2010.pd f>. Acesso em: 30 mar. 2011.

BRASIL. Ministério da Saúde. Saúde mental no SUS: os Centros de Atenção Psicossocial. Disponível em: <http://www.ccs.saude.gov.br/saude_mental/pdf/SM_Sus.pdf>.

Acesso em: 23 fev. 2011.

CADORE, C.; PALMA, C. M. S.; DASSOLER. V. A. Sobre o Projeto Terapêutico Singular: um dispositivo clínico ou um procedimento burocrático? In: Anais da 3a J ornada I nterdisciplinar em saúde, 2010, Santa Maria, RS.

CAMPOS, G. W. S. Equipes de referência e apoio especialização matricial: um ensaio sobre a reorganização do trabalho em saúde. Ciência \& Saúde Coletiva, Rio de Janeiro, v. 4, n. 2, p. 393-403, 1999.

FURTADO, J. P. Equipes de Referência: arranjo institucional para potencializar a colaboração entre disciplinas e profissões. Interface - Comunicação, Saúde, Educação, Botucatu, v. 11, n. 22, p. 2395, maio/agosto 2007.

FURTADO, J. P.; MIRANDA, L. O dispositivo "técnicos de referência" nos equipamentos substitutivos em saúde mental e o uso da psicanálise winnicottiana. Revista Latinoamericana de Psicopatologia Fundamental, São Paulo, v. IX, n. 3, p. 508-524, setembro 2006.

LUSSI, I. A. O.; PEREIRA. M. A. O.; PEREIRA JUNIOR, A. A proposta de reabilitação psicossocial de Saraceno: um modelo de autoorganização?. Revista Latinoamericana de Enfermagem, Ribeirão Preto, v. 14, n. 3, maio/junho 2006.

MIRANDA, L.; ONOCKO CAMPOS, R. T. Análise do trabalho de referência em Centros de Atenção Psicossocial. Revista de Saúde Pública, São Paulo, v. 42, n. 5, outubro 2008.

MIRANDA, L.; ONOCKO CAMPOS, R. T. Análise das equipes de referência em saúde mental: uma perspectiva de gestão da clínica.

Cadernos de Saúde Pública, Rio de Janeiro, v. 26, n. 6, p. 11531162, 2010.

POPE, C.; MAYS, N. Pesquisa qualitativa na atenção à saúde. Porto Alegre: Artmed, 2005.

SILVA, E. A.; COSTA, I. I. O profissional de referência em Saúde Mental: das responsabilizações ao sofrimento psíquico. Revista Latinoamericana de Psicopatologia Fundamental, São Paulo, v. 13 , n. 4, p. 635-647, dezembro 2010.

TENÓRIO, F. A reforma psiquiátrica brasileira, da década de 1980 aos dias atuais: história e conceitos. História, Ciências, Saúde Manguinhos, Rio de Janeiro, v. 9, n. 1, janeiro/abril 2002.

Endereço para correspondência

Brunna Lisita Chaves 
Pontifícia Universidade Católica de Goiás - Av, Universitária 1.440, Setor

Universitário, Goiânia-GO, CEP: 74605-010

Endereço eletrônico: brunna_lisita@hotmail.com

\section{Renata F. Pegoraro}

Pontifícia Universidade Católica de Goiás - Programa de Pós-Graduação em Ciências Ambientais e Saúde.

Rua 232, № 128 - Setor Universitário - Área V - 3o andar - CEP 74605-140, Goiânia - GO.

Endereço eletrônico: rfpegoraro@yahoo.com.br

Recebido em: 14/02/2012

Reformulado em: 04/01/2013

Aceito para publicação em: 10/01/2013

Acompanhamento do processo editorial: Rita Maria Manso de Barros

\section{Notas}

* Psicóloga formada pela PUC Goiás, Goiânia, GO.Especialista em Psicologia da Saude e Hospitalar pelo IEP/ACCG - Instituto de Ensino e Pesquisa da Associação de Combate ao Câncer de Goiás

** Professora Adjunta da PUC Goiás, Goiânia, GO. Docente do Mestrado em Ciências Ambientais e Saúde da PUC Goiás. Doutora em Psicologia pela USP Ribeirão Preto. Especialista em Saúde Coletiva pela UFSCar 